\title{
Evaluation of staff performance and interpretation of the screening program for prevention of thalassemia
}

\author{
Simaporn Prommetta ${ }^{1,2}$, Kanokwan Sanchaisuriya² ${ }^{2}$ Goonnapa Fucharoen², Supawadee Yamsri², Attawut Chaiboonroeng ${ }^{2}$, Supan \\ Fucharoen ${ }^{* 2}$ \\ ${ }^{1}$ Medical Science Program, Graduate School, Khon Kaen University, Thailand \\ ${ }^{2}$ Centre for Research and Development of Medical Diagnostic Laboratories, Faculty of Associated Medical Sciences, Khon Kaen \\ University, Thailand.
}

*Corresponding author: supan@kku.ac.th

\begin{abstract}
Introduction: Thalassemia screening program has been implemented for years in Southeast Asia, but no external quality assessment program has been established. We have developed and initiated the proficiency testing (PT) program for the first time in Thailand with the aim to assess the screening performance of laboratory staff and their competency in interpretation of the screening results.

Materials and methods: Three PT cycles per year were organized. From the first to the third cycle of the PT scheme, a total number of participant laboratories increased from 59 to 67. In each cycle, 2 PT items (assigned as blood samples of the couple) were provided. Performance evaluation was based on the accuracy of screening results, i.e. mean corpuscular volume (MCV), mean corpuscular haemoglobin (MCH) and the dichlorophenolindophenol (DCIP) test for haemoglobin E, including the competency in interpretation of screening results and assessment of foetal risk. Performance was assessed by comparing the participants' result against the assigned value.
\end{abstract}

Results: Of all 3 cycles, most laboratories reported acceptable MCV and MCH values. From the first to the third cycle, incorrect DCIP test and misinterpretation rates were decreased while incorrect risk assessment varied by cycle to cycle. Combining the accuracy of thalassemia screening and the competency in interpretation and risk assessment, approximately half of participants showed excellent performance.

Conclusion: Improved performance observed in many laboratories reflects the achievement and benefit of the PT program which should be regularly provided.

Key words: laboratory proficiency testing; thalassemia; quality control

\section{Introduction}

Amongst the inherited blood disorders in Southeast Asia, thalassemia is the most common one. It is also considered as an emerging burden of health among the world population $(1,2)$. In this region, although there are several forms of thalassemia, only three severe forms namely haemoglobin $(\mathrm{Hb})$ Bart's hydrops fetalis (homozygous $a^{0}$-thalassemia), homozygous $\beta$-thalassemia and $\mathrm{Hb} \mathrm{E}-\beta$ thalassemia are of major concern, requiring appropriate prevention and control program (3). As such, a prevention and control program has long been implemented. The ultimate goal of the program is to reduce the incidence of these three severe diseases. The program comprises three steps: 1) screening for thalassemia in pregnant women and their husbands, 2) providing genetic counselling to the at-risk couples, and 3) offering after genetic counselling, option for a prenatal diagnosis and termination of pregnancy with affected foetus $(3,4)$.

In Thailand, screening for thalassemia is obligatory and financed by the National Health Security Office. The national policy demands all primary health care facilities providing thalassemia screening to all pregnant women and their husbands at 
the first visits. Screening procedures include the measurement of mean corpuscular volume (MCV) and/or mean corpuscular haemoglobin $(\mathrm{MCH})$ to identify suspected carriers of $a^{0}$-thalassemia and $\beta$-thalassemia, and the dichlorophenolindophenol (DCIP) test for $\mathrm{Hb} \mathrm{E}(5,6)$. Based on this screening strategy, blood samples of positive cases are sent to referral centres to investigate further with $\mathrm{Hb}$ and DNA analyses for definite diagnosis. For those with negative results, no further investigation is required. Therefore, it is crucial that initial screening must be accurate. Due to the lack of proficiency testing scheme, information on the performance of initial thalassemia screening of laboratories in the country is not available so far.

In this study, we have developed and initiated the proficiency testing (PT) program for the first time in Thailand aiming to assess the screening performance of laboratory staff and their competency in interpretation of the screening results. Because of the complexity of thalassemia in the country, we hypothesized that there might be incorrect interpretation and/or risk assessment among laboratory staff. Information obtained from the study would inspire health authorities of all similar settings to establish the PT program within the region.

\section{Materials and methods}

\section{Preparation of PT items for thalassemia screening and the participants}

Ethical approval of the study protocol was obtained from the Ethical Committee of Khon Kaen University, Thailand (HE582243). Appropriate human blood samples were selectively collected and used in preparation of the PT items. After informed-consent was obtained, 15 - $20 \mathrm{~mL}$ peripheral blood samples anticoagulated with acid citrate dextrose $(A C D)$ were collected from two donors, i.e. normal individual (normal Hb-type with normal MCV and $\mathrm{MCH}$ ) and $\mathrm{Hb} \mathrm{E}$ carrier. Only one sample from each donor was taken. Baseline values of MCV and MCH were measured using Sysmex XS-800i haematology analyser (Sysmex, Kobe, Japan) and Coulter Hematology Analyzers (COULTER $^{\circledR}$ LH780 Hematology Analyzer, Beckman Coul- ter, USA). Then, blood samples were preserved with the phosphate-adenine-glucose-guanosine-saline-mannitol (PAGGSM) reagent as described previously (7). In brief, one volume of PAGGSM was added into 3.5 volumes of blood sample and mixtures were mixed continuously on a rotating mixer at $400 \times \mathrm{g}$ for 60 minutes. After storing at $2-6^{\circ} \mathrm{C}$ for 48 hours for stabilization of red blood cell (RBC) parameters, aliquots of the mixtures were distributed on ice to the participants for analysis within 1 week. Prior to distribution, two aliquots of each PT item were randomly selected to perform MCV and $\mathrm{MCH}$ measurement and DCIP test. Homogeneity and stability of the PT items prepared were tested according to the ISO/IEC 17043 (8). General characteristics of the PT items prepared were summarized in Tables 1 and 2. To minimize variation in the types of haematology analysers used (9), members of the two manufacturers, i.e. the Sysmex Co., Ltd. and the Beckman Coulter Co., Ltd., were invited. These two companies agreed with the PT program. The representatives of each company were responsible for invitation and transportation of PT items on time to the invited participants.

\section{The proficiency testing scheme}

Three cycles of the PT program were applied during June 2015 to May 2016. From the first to the third cycle of the PT scheme, numbers of participant laboratories were 30, 26 and 27 for group of participants using Sysmex Hematology Analyzer series, in cycles 1, 2, and 3, respectively. In contrast, number of those participants using Beckman Coulter Analyzer series increased from 29 in cycle 1 , to 39 in cycle 2 , and to 40 in cycle 3 . Participants were asked to measure MCV and $\mathrm{MCH}$ values and perform the DCIP test within 24 hours of receiving the PT items. In brief, laboratory staff was asked to add $0.02 \mathrm{ml}$ of each blood sample into $2 \mathrm{ml}$ of DCIP reagent, and incubate the mixture at $37^{\circ} \mathrm{C}$ for 15 minutes. After stopping the reaction by adding $0.02 \mathrm{ml}$ of the stop-solution, laboratory staff reported the DCIP screening results according to the turbidity observed by naked-eye.

In each cycle, 2 PT items were prepared and assigned as blood samples of pregnant woman, and 
TABLE 1. Characteristics of the PT items provided for participants using Coulter hematology analyzer

\begin{tabular}{|c|c|c|c|c|c|c|}
\hline \multirow{2}{*}{ Characteristics } & \multicolumn{2}{|c|}{ Cycle 1} & \multicolumn{2}{|c|}{ Cycle 2} & \multicolumn{2}{|c|}{ Cycle 3} \\
\hline & QCM-1A & QCM-1B & QCM-2A & QCM-2B & QCM-3A & QCM-3B \\
\hline Assigned code & Husband & $\begin{array}{c}\text { Pregnant } \\
\text { woman }\end{array}$ & Husband & $\begin{array}{c}\text { Pregnant } \\
\text { woman }\end{array}$ & Husband & $\begin{array}{c}\text { Pregnant } \\
\text { woman }\end{array}$ \\
\hline $\operatorname{MCV}(\mathbf{f L})^{*}$ & $91.1 \pm 1.5$ & $78.1 \pm 0.9$ & $69.0 \pm 0.5$ & $73.1 \pm 0.3$ & $65.7 \pm 0.3$ & $64.1 \pm 0.5$ \\
\hline $\mathbf{M C H}(\mathbf{p g})^{*}$ & $29.3 \pm 0.2$ & $25.1 \pm 0.2$ & $21.7 \pm 0.4$ & $23.6 \pm 0.2$ & $21.3 \pm 1.0$ & $20.5 \pm 0.2$ \\
\hline DCIP Test & Negative & Positive & Negative & Positive & Positive & Positive \\
\hline $\begin{array}{l}\text { Summary of the } \\
\text { combined test }^{\dagger}\end{array}$ & $-/-$ & $+/+$ & $+/-$ & $+/+$ & $+/+$ & $+/+$ \\
\hline $\begin{array}{l}\text { Interpretation } \\
\text { based on } \\
\text { screening results }\end{array}$ & $\begin{array}{c}\text { Non-thal or } \\
\text { non-clinically } \\
\text { significant thal }\end{array}$ & $\begin{array}{c}\text { Suspected Hb E } \\
\text { with or without } \\
\text { a-thal and/or } \\
\beta \text {-thal }\end{array}$ & $\begin{array}{c}\text { Suspected } \\
\text { a-thal and/or } \\
\beta \text {-thal }\end{array}$ & $\begin{array}{c}\text { Suspected Hb E } \\
\text { with or without } \\
\text { a-thal and/or } \\
\beta \text {-thal }\end{array}$ & $\begin{array}{l}\text { Suspected } \\
\text { Hb E with or } \\
\text { without a-thal } \\
\text { and/or } \beta \text {-thal }\end{array}$ & $\begin{array}{c}\text { Suspected Hb E } \\
\text { with or without } \\
\text { a-thal and/or } \\
\beta \text {-thal }\end{array}$ \\
\hline Fetal risk ${ }^{\ddagger}$ & & & $\begin{array}{r}\text { Homozygou } \\
\text { Homozygou } \\
\beta \text {-thalas }\end{array}$ & $\begin{array}{l}a_{0} \text {-thalassemia } \\
\beta \text {-thalassemia } \\
\text { mia / Hb E }\end{array}$ & $\begin{array}{r}\text { Homozygous } \\
\text { Homozygous } \\
\beta \text {-thalasse }\end{array}$ & $\begin{array}{l}a_{0} \text {-thalassemia } \\
\beta \text {-thalassemia } \\
\text { mia / Hb E }\end{array}$ \\
\hline
\end{tabular}

*Measured using COULTER ${ }^{\circ}$ LH780 (Beckman Coulter, USA).

Either MCV/DCIP or MCH/DCIP; MCV < $80 \mathrm{fL}$ or MCH < 27 pg was considered positive (- / -; negative for both test, + / -; positive for MCV (or MCH) but negative DCIP, - / +; negative MCV (or MCH) but positive DCIP, + / +; positive for both tests).

${ }^{\ddagger}$ Based on screening results of pregnant woman and her husband; diseases at risk being assessed were homozygous $a_{0}$-thalassemia, homozygous $\beta$-thalassemia and $\beta$-thalassemia / $\mathrm{Hb} \mathrm{E}$.

PT - proficiency testing; MCV - mean corpuscular volume; MCH - mean corpuscular haemoglobin; DCIP - dichlorophenolindophenol.

TABLE 2. Characteristics of the PT items provided for participants using the Sysmex haematology analyser.

\begin{tabular}{|c|c|c|c|c|c|c|}
\hline \multirow{2}{*}{ Characteristics } & \multicolumn{2}{|c|}{ Cycle 1} & \multicolumn{2}{|c|}{ Cycle 2} & \multicolumn{2}{|c|}{ Cycle 3} \\
\hline & QCM-1A & QCM-1B & QCM-2A & QCM-2B & QCM-3A & QCM-3B \\
\hline Assigned code & Husband & $\begin{array}{l}\text { Pregnant } \\
\text { woman }\end{array}$ & Husband & $\begin{array}{l}\text { Pregnant } \\
\text { woman }\end{array}$ & Husband & Pregnant woman \\
\hline $\operatorname{MCV}(\mathbf{f L}) *$ & $85.2 \pm 2.2$ & $61.3 \pm 1.1$ & $63.7 \pm 0.5$ & $74.9 \pm 0.8$ & $58.8 \pm 1.6$ & $89.1 \pm 0.7$ \\
\hline MCH (pg)* & $27.9 \pm 0.3$ & $19.8 \pm 0.1$ & $20.1 \pm 0.2$ & $24.5 \pm 0.7$ & $21.0 \pm 0.1$ & $27.8 \pm 0.2$ \\
\hline DCIP Test & Negative & Positive & Negative & Positive & Positive & Negative \\
\hline $\begin{array}{l}\text { Summary of the } \\
\text { combined test }^{\dagger}\end{array}$ & $-1-$ & $+/+$ & $+/-$ & $+/+$ & $+/+$ & $-1-$ \\
\hline $\begin{array}{l}\text { Interpretation based } \\
\text { on screening results }\end{array}$ & $\begin{array}{c}\text { Non-thal or } \\
\text { non-clinically } \\
\text { significant thal }\end{array}$ & $\begin{array}{c}\text { Suspected Hb E } \\
\text { with or without } \\
\text { a-thal and/or } \\
\beta \text {-thal }\end{array}$ & $\begin{array}{c}\text { Suspected } \\
\text { a-thal and/or } \\
\beta \text {-thal }\end{array}$ & $\begin{array}{l}\text { Suspected } \\
\mathrm{Hb} \text { E with or } \\
\text { without a-thal } \\
\text { and/or } \beta \text {-thal }\end{array}$ & $\begin{array}{c}\text { Suspected Hb E } \\
\text { with or without } \\
\text { a-thal and/or } \\
\beta \text {-thal }\end{array}$ & $\begin{array}{c}\text { Non-thal or } \\
\text { non-clinically } \\
\text { significant thal }\end{array}$ \\
\hline
\end{tabular}

Fetal risk ${ }^{\ddagger}$

No risk
Homozygous $\mathrm{a}_{0}$-thalassemia

Homozygous $\beta$-thalassemia

$\beta$-thalassemia / $\mathrm{Hb} \mathrm{E}$
No risk

*Measured using Sysmex XS-800i (Sysmex, Kobe, Japan).

${ }^{\dagger}$ Either MCV/DCIP or MCH/DCIP; MCV < $80 \mathrm{fL}$ or MCH < 27 pg was considered positive (- / -; negative for both test, + / -; positive for MCV (or MCH) but negative DCIP, - / +; negative MCV (or MCH) but positive DCIP, + / +; positive for both tests).

${ }^{\ddagger}$ Based on screening results of pregnant woman and her husband; diseases at risk being assessed were homozygous $a_{0}$-thalassemia, homozygous $\beta$-thalassemia and $\beta$-thalassemia / $\mathrm{Hb} \mathrm{E}$.

PT - proficiency testing; MCV - mean corpuscular volume; MCH - mean corpuscular hemoglobin; DCIP - dichlorophenolindophenol. 
her husband. Along with the PT items, detail instructions, necessary information and report form were provided for participants. The performance assessment comprised 3 parts; Part I: Accuracy of MCV \& MCH measurements and DCIP testing, Part II: Competency in interpretation of the screening results, and Part III: Competency in assessing the risk of foetus of having the three severe thalassemia diseases (Table 3).

\section{Evaluation criteria}

Different evaluation criteria were applied, as described below.

\section{Accuracy of initial screening test}

To minimize variation associated with different haematology analysers, performance of MCV and $\mathrm{MCH}$ measurements was evaluated separately for the 2 groups of participants (9). Accuracy of MCV and $\mathrm{MCH}$ measurements were evaluated against the assigned values obtained from the consensus values of each participant group. Assigned values were calculated using robust statistical methods as recommended by the ISO 13528 (10). A z-score was calculated directly from the result reported by the participant in relation to an acceptable varia- tion of all results to the assigned value [(participant result - assigned value) / standard deviation] for proficiency assessment. A z-score within - 2 to 2 was considered acceptable. A bar-chart of $z-$ score was constructed to demonstrate performance of all participants. For qualitative DCIP test for $\mathrm{Hb} \mathrm{E}$, the result of each participant (either positive or negative) was compared directly with the assigned value defined by $\mathrm{Hb}$ analysis using capillary electrophoresis system (Capillarys II Flex Piecing, Sebia corp., France) at our laboratory (11). Proportions of participants reporting incorrect result were calculated and compared between cycles, i.e. cycles 1 and 2, cycles 1 and 3, and cycles 2 and 3 .

\section{Competency in interpretation of thalassemia screening}

Interpretation of competency was evaluated according to standard screening guidelines, using MCV and/or MCH in combination with DCIP test $(5,6)$. There are 4 categories of the screening results and interpretations; i.e. category $\mathrm{A}(\mathrm{MCV}>80$ $\mathrm{fL}$ or $\mathrm{MCH}>27 \mathrm{pg}$ with negative DCIP or (-/-) variety): non-thalassemia or non-clinically significant thalassemia; category $\mathrm{B}(\mathrm{MCV}<80 \mathrm{fL}$ or $\mathrm{MCH}<27$ pg with negative DCIP or (+/-) variety): suspected

TABLE 3. Report form for the participants

\begin{tabular}{|c|c|c|c|}
\hline \multicolumn{4}{|c|}{ Part I: Screening result (please check $\checkmark$ in the $\square$ as appropriate). } \\
\hline \multirow[t]{2}{*}{ QCM No. 1 (PW) } & $\mathrm{MCV} / \mathrm{MCH}$ result & $\square$ Positive & $\square$ Negative \\
\hline & DCIP-test result & $\square$ Positive & $\square$ Negative \\
\hline \multirow[t]{2}{*}{ QCM No. 2 (Husband) } & $\mathrm{MCV} / \mathrm{MCH}$ result & $\square$ Positive & $\square$ Negative \\
\hline & DCIP-test result & $\square$ Positive & $\square$ Negative \\
\hline
\end{tabular}

Part II: Interpretation of screening results (please check $\checkmark$ in the $\square$ as appropriate).

- QCM No. 1 (PW) $\square$ A $\square$ B $\quad \square$ C $\quad \square$ D

- QCM No.2 (Husband) $\square$ A $\square$ B $\square$ C $\square$ D

where A: Non-thalassemia or non-clinically significant thalassemia

B: Suspected $\alpha$-thalassemia and/or $\beta$-thalassemia

C: Suspected $\mathrm{Hb}$ E trait

D: Suspected $\mathrm{Hb}$ E with or without $\alpha$ - and/or $\beta$-thalassemia

\footnotetext{
Part III: Fetal risk assessment (please check $\checkmark$ in the $\square$ as appropriate. (If relevant, more than 1 category can be selected). Disease at risk of the fetus: $\square$ A $\square$ B $\square$ C $\square$ D

where A: Hb Bart's hydrops fetalis

B: Homozygous $\beta$-thalassemia

C: $\mathrm{Hb}$ E- $\beta$-thalassemia disease

D: No risk for the 3 diseases mentioned above
}

PW - pregnant woman. 
$a^{0}$-thalassemia and/or $\beta$-thalassemia; category $C$ (MCV > $80 \mathrm{fL}$ or $\mathrm{MCH}>27 \mathrm{pg}$ with positive DCIP or (-/+) variety): suspected $\mathrm{Hb} \mathrm{E}$ trait; category $\mathrm{D}$ (MCV $<80 \mathrm{fL}$ or $\mathrm{MCH}<27 \mathrm{pg}$ with positive DCIP or $(+/+)$ variety): suspected $\mathrm{Hb} \mathrm{E}$ with or without $\mathrm{a}-$ and/or $\beta$-thalassemia. These 4 categories were provided in the report form of the participants, allowing them to select an appropriate category based on the screening result of each PT item.

\section{Competency in risk assessment of the foetus}

Each participant was asked to assess the disease at-risk of the foetus by combining screening results obtained from the 2 PT items (which were assigned respectively as pregnant woman and her husband). The at-risk diseases being assessed included $\mathrm{A}: \mathrm{Hb}$ Bart's hydrops fetalis (homozygous $a^{0}$-thalassemia); $B$ : homozygous $\beta$-thalassemia; $C$ : $\mathrm{Hb}$ E- $\beta$-thalassemia and D: No risk for the three severe thalassemia diseases. Possible patterns of screening results of the couples and diseases at risk of the foetuses are listed (Table 4).

Table 4. Possible diseases at-risk of the foetus based on the screening results of the couple

\begin{tabular}{|c|c|c|}
\hline \multicolumn{2}{|c|}{$\begin{array}{c}\text { Screening result (MCV or } \\
\mathrm{MCH} / \mathrm{DCIP})^{*}\end{array}$} & \multirow{2}{*}{ Disease at-risk of the foetus } \\
\hline $\begin{array}{l}\text { Result of one } \\
\text { of the couple }\end{array}$ & $\begin{array}{l}\text { Result of } \\
\text { the other }\end{array}$ & \\
\hline \multirow{3}{*}{$+/+$} & $+/+$ & $\begin{array}{l}\text { Hb Bart's hydrops fetalis } \\
\text { Homozygous } \beta \text {-thalassemia } \\
\text { Hb E- } \beta \text {-thalassemia disease }\end{array}$ \\
\hline & $+/-$ & $\begin{array}{l}\text { Hb Bart's hydrops fetalis } \\
\text { Homozygous } \beta \text {-thalassemia } \\
\text { Hb E- } \beta \text {-thalassemia disease }\end{array}$ \\
\hline & $-/+$ & $\mathrm{Hb} \mathrm{E}-\beta$-thalassemia disease \\
\hline \multirow[t]{2}{*}{$+/-$} & $+/-$ & $\begin{array}{l}\text { Hb Bart's hydrops fetalis } \\
\text { Homozygous } \beta \text {-thalassemia }\end{array}$ \\
\hline & $-1+$ & $\mathrm{Hb} \mathrm{E}-\beta$-thalassemia disease \\
\hline \multirow{2}{*}{$-/+$} & $-1+$ & No risk for the 3 diseases \\
\hline & $-/-$ & No risk for the 3 diseases \\
\hline
\end{tabular}

* (+ and -$)$ before the slash (/) indicate positive for MCV or $\mathrm{MCH}$ (either $\mathrm{MCV}<80 \mathrm{fL}$ or $\mathrm{MCH}<27 \mathrm{pg}$ ) and negative (MCV $>80 \mathrm{fL}$ or $\mathrm{MCH}>27 \mathrm{pg}$ ), respectively. (+ and -) after the slash (/) indicates the result of dichlorophenolindophenol (DCIP) screening test. ${ }^{\dagger}$ Consider for the three target thalassemia diseases only.
TABLE 5. Evaluation of performance levels of the participants

\begin{tabular}{|c|c|}
\hline Level & Description \\
\hline Excellent: & $\begin{array}{l}\text { Acceptable MCV \& MCH values and } \\
\text { correct DCIP test, correct interpretation of } \\
\text { thalassemia screening and risk assessment } \\
\text { of the foetal. }\end{array}$ \\
\hline Good: & $\begin{array}{l}\text { Acceptable MCV \& MCH values and } \\
\text { correct DCIP test, correct interpretation of } \\
\text { thalassemia screening, but incorrect risk } \\
\text { assessment of the foetus. }\end{array}$ \\
\hline Fair: & $\begin{array}{l}\text { Acceptable MCV \& MCH values and correct } \\
\text { DCIP test, but incorrect interpretation of } \\
\text { thalassemia screening and risk assessment } \\
\text { of the foetus. }\end{array}$ \\
\hline Poor: & $\begin{array}{l}\text { Incorrect result of MCV or } \mathrm{MCH} \text { or DCIP. No } \\
\text { further evaluation is performed. }\end{array}$ \\
\hline
\end{tabular}

MCV - mean corpuscular volume; MCH - mean corpuscular hemoglobin; DCIP - dichlorophenolindophenol.

As for DCIP test, the proportions of participants reporting incorrect results (incorrect interpretation of thalassemia screening as well as incorrect risk assessment) were calculated and compared between cycles.

\section{Performance levels of the participants}

The overall performance of each participant was defined according to the above three evaluation criteria; accuracy of screening tests (MCV, MCH and DCIP), competency in interpretation of screening results and competency in risk assessment of the fetus. Four levels of performance are given in Table 5.

\section{Statistical analysis}

Outcome variables being evaluated included 'zscore' of MCV and MCH, DCIP result, interpretation of screening test, risk assessment, and performance level. All data obtained from participants were entered into Excel spreadsheets. For quantitative test (MCV and $\mathrm{MCH}$ measurements), the robust statistical analysis (Algorithm A; ISO 13528) was applied to identify outliers (10). These analyses were performed with the Excel 2013. For qualitative tests, proportions of participants reporting incorrect results (incorrect interpretation of thalassemia screening as well as incorrect risk assess- 
ment) were calculated and compared between cycles using z-test. Statistical comparison was performed using the Minitab Statistical Software version 12.2 (Minitab Inc, Pennsylvania, USA). A P-value $<0.05$ was considered significant.

\section{Results}

\section{Accuracy of MCV \& MCH measurements and DCIP test}

Bar charts of z-scores of participants are illustrated in Figure 1 (for Beckman Coulter Analyzers) and Figure 2 (for Sysmex Haematology Analysers). The majority of participants in both groups could report acceptable MCV and MCH values, as indicated by $z< \pm 2$. For DCIP test, the proportion of laboratories reporting incorrect result was $6 / 59$ in the first cycle, 4/65 in the second cycle, and 1/67 in the third cycle of the PT scheme (Table 6). There was no statistically significant difference between cycles.
Competency in interpretation and assessing the risk of foetus

Incorrect interpretation of screening results and risk assessment of the foetus are shown in Table 6. In the first cycle, 20 out of 59 participants interpreted screening results incorrectly. The proportion of incorrect interpretation decreased to $16 / 65$ in second cycle, and to $14 / 67$ in third cycle. However, no statistically significant difference between cycles was obtained.

The competency in assessing the risk of foetus based on screening test results showed fluctuation. A high proportion of incorrect risk assessment was observed in second cycle (37/65) whereas in cycles 1 and 3, the proportions of incorrect risk assessment (11/59 for cycle 1 and $13 / 67$ for cycle 3) were significantly lower than that of cycle 2.

Cycle 1

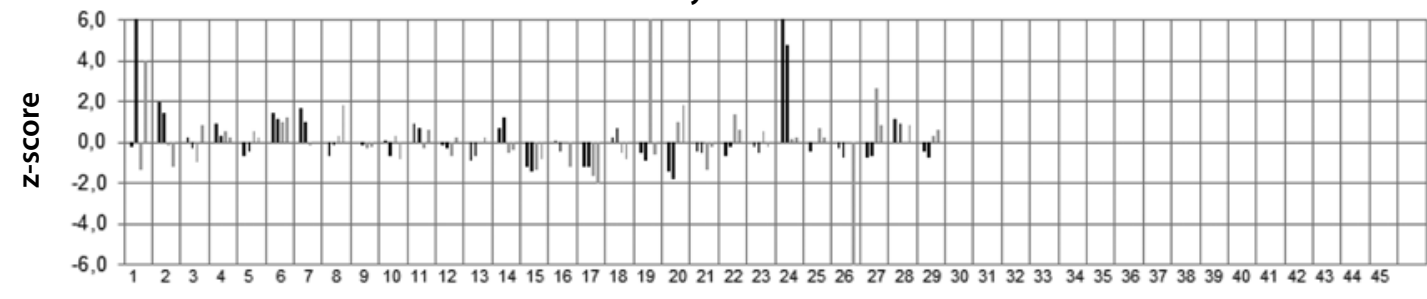

Cycle 2

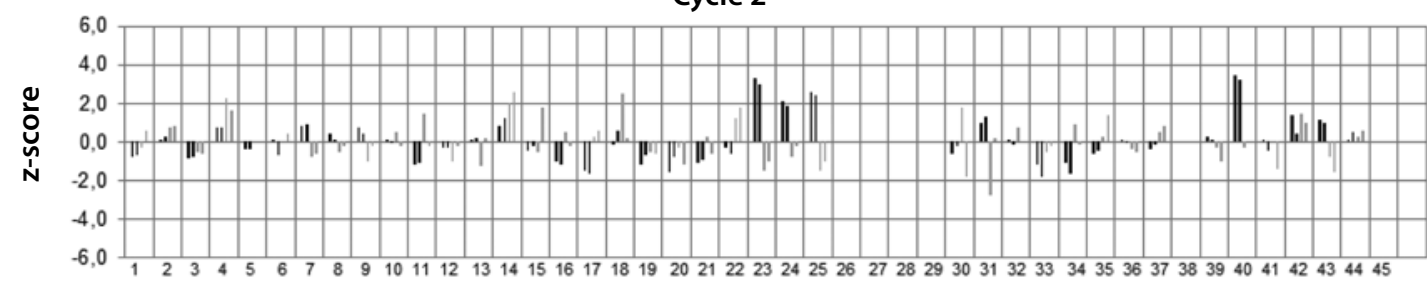

Cycle 3

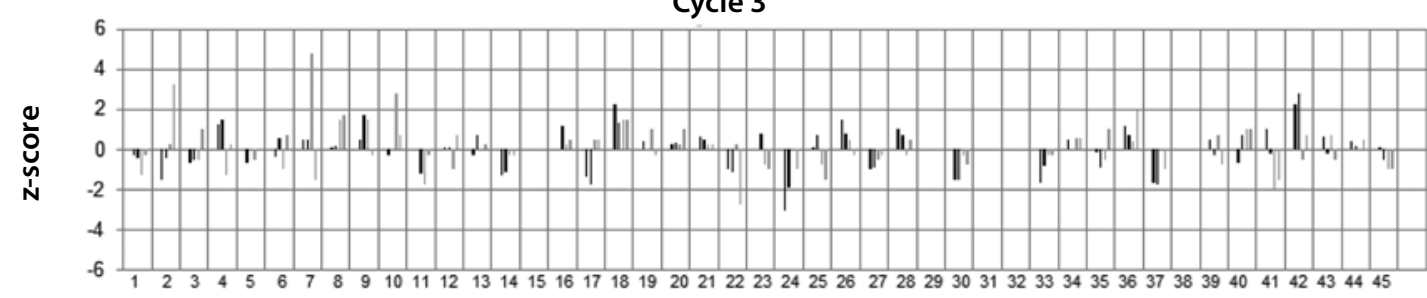

FiguRE 1. Bar charts of $z$-scores of participants of the Beckman Coulter

$\mathrm{Y}$ - and X-axes represent z-score, and participant number, respectively. Black and grey lines respectively represent z-score of MCV and MCH obtained from 2 PT items. Laboratories participating in the first cycle were coded as numbers 1-29. New laboratories participating in the second and the third cycles were coded from 30-45. In the second cycle, 4 participants (no. 26-29) did not submit their results. 
Cycle 1

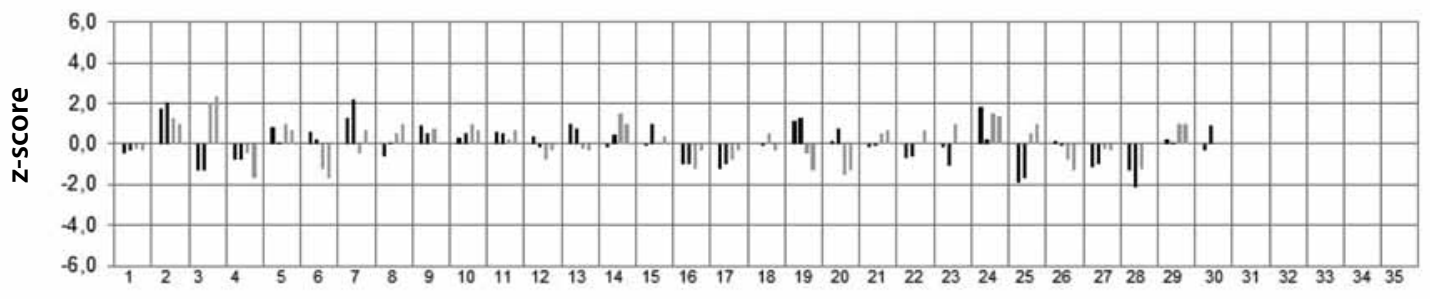

Cycle 2

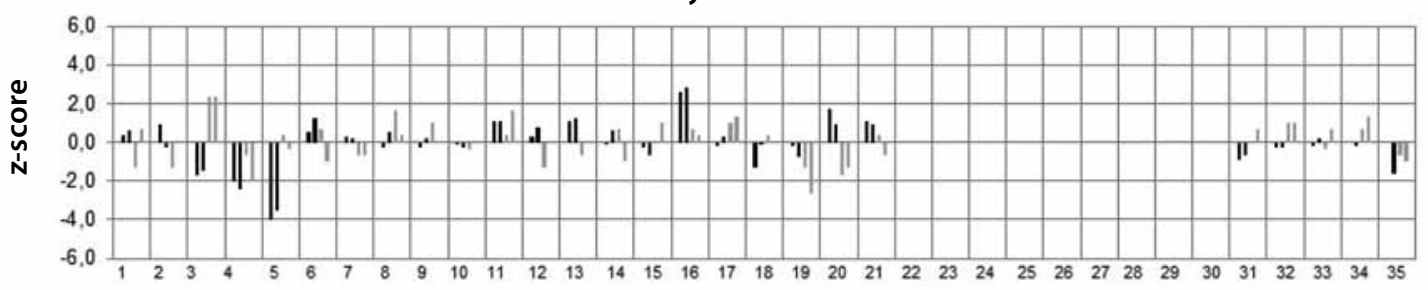

Cycle 3

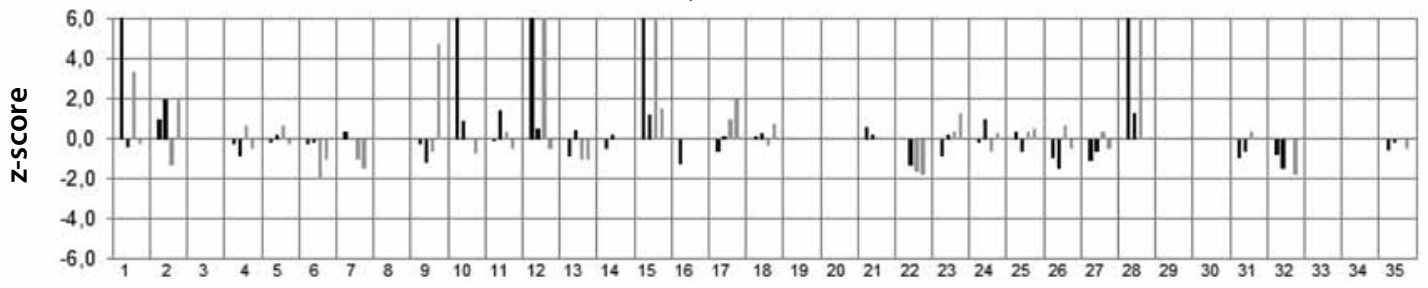

Figure 2. Bar charts of z-scores of participants of the Sysmex

Y- and X-axes represent Z-score, and participant number, respectively. Black and grey lines respectively represent z-score of MCV and MCH obtained from 2 PT items. Laboratories participating in the first cycle were coded as numbers 1-30. New laboratories participating in the second and the third cycles were coded from 31-35. In the second and third cycles, 9 and 8 participants did not submit their results (no. 22-30 for cycle 2 and no.3, 8, 19, 20, 29, 30, 33, 34 for cycle 3).

TABLE 6. Laboratories reporting incorrect results

\begin{tabular}{lccc}
\hline Assessing item & Cycle 1 & Cycle 2 & Cycle 3 \\
\hline DCIP test & $6 / 59(10.2)$ & $4 / 65(6.2)$ & $1 / 67(1.5)$ \\
Interpretation of screening results & $20 / 59(33.9)$ & $16 / 65(24.6)$ & $14 / 67(20.9)$ \\
Risk assessment of the foetus & $11 / 59(18.6)$ & $37 / 65(56.9)^{*}$ & $13 / 67(19.4)^{\dagger}$ \\
\hline
\end{tabular}

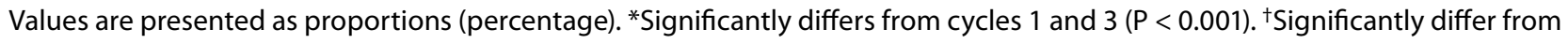
cycle $2(P<0.001)$. DCIP - dichlorophenolindophenol.

\section{Proficiency levels of participants}

Figure 3 illustrates the proficiency levels of participants in 3 cycles of the PT scheme. Excellent performance was obtained in 28/59 (47.5\%) of participants in cycle 1, 25/65 (38.5\%) in cycle 2 , and 38/67 $(56.7 \%)$ in cycle 3 . In contrast, poor performance was respectively noted at 14/59 (23.7\%), 17/65
(26.2\%) and 14/67 (20.9\%) in the cycles 1, 2 and 3 . Performance of individual participant in each round is also illustrated (Figure 4). A few laboratories could maintain their excellent performance for all 3 cycles, e.g. participant numbers 1-5 of the first group using Beckman Coulter Haematology Ana- 


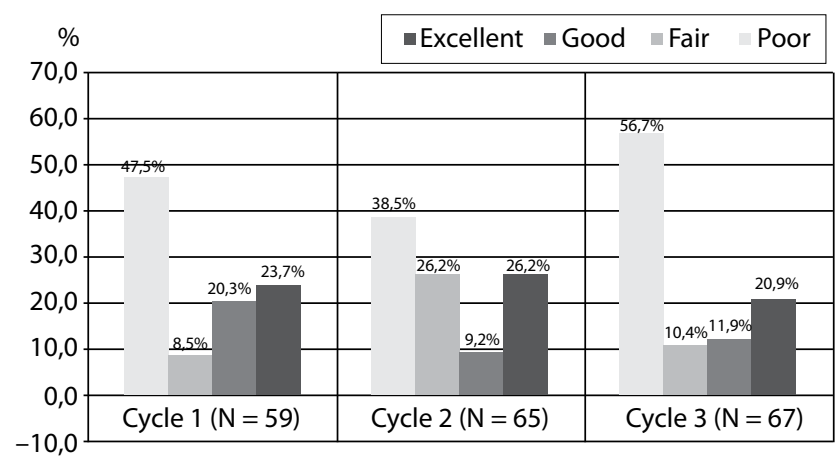

Figure 3. Proficiency levels of participants in 3 cycles of the PT scheme PT - proficiency testing.

lysers and participant numbers 1-2 of the second group with Sysmex Haematology Analysers. However, it could be seen that many of them improved their performance in the second and/or the third cycle of the PT scheme.

\section{Discussion}

In this study, we report the results of PT program for thalassemia screening initiated for the first time in our country. It was found that approximately half of participants had excellent performance and most of the non-excellent performances are due to incorrect interpretation and/or risk assessment. Our PT schemes included quantitative, qualitative and interpretive tests. For quantitative test, although most laboratories could report acceptable MCV and MCH values, falsely high values were occasionally seen, resulting in unacceptable z-scores of higher than 2 (Figures 1 and 2). This information is especially important for thalassemia screening in that the falsely high values of MCV \& MCH could lead to false negative in thalassemia screening. In general, false positive might occur at a thalassemia screening as reported previously $(5,6,12)$, but this does not matter since major concern would be false negative. It is crucial therefore that false negative should be kept at minimum since this can result in an incidence of newborn with severe thalassemia syndromes. The evaluation results obtained from the PT program are therefore helpful for participants to identify and fix such serious problems.
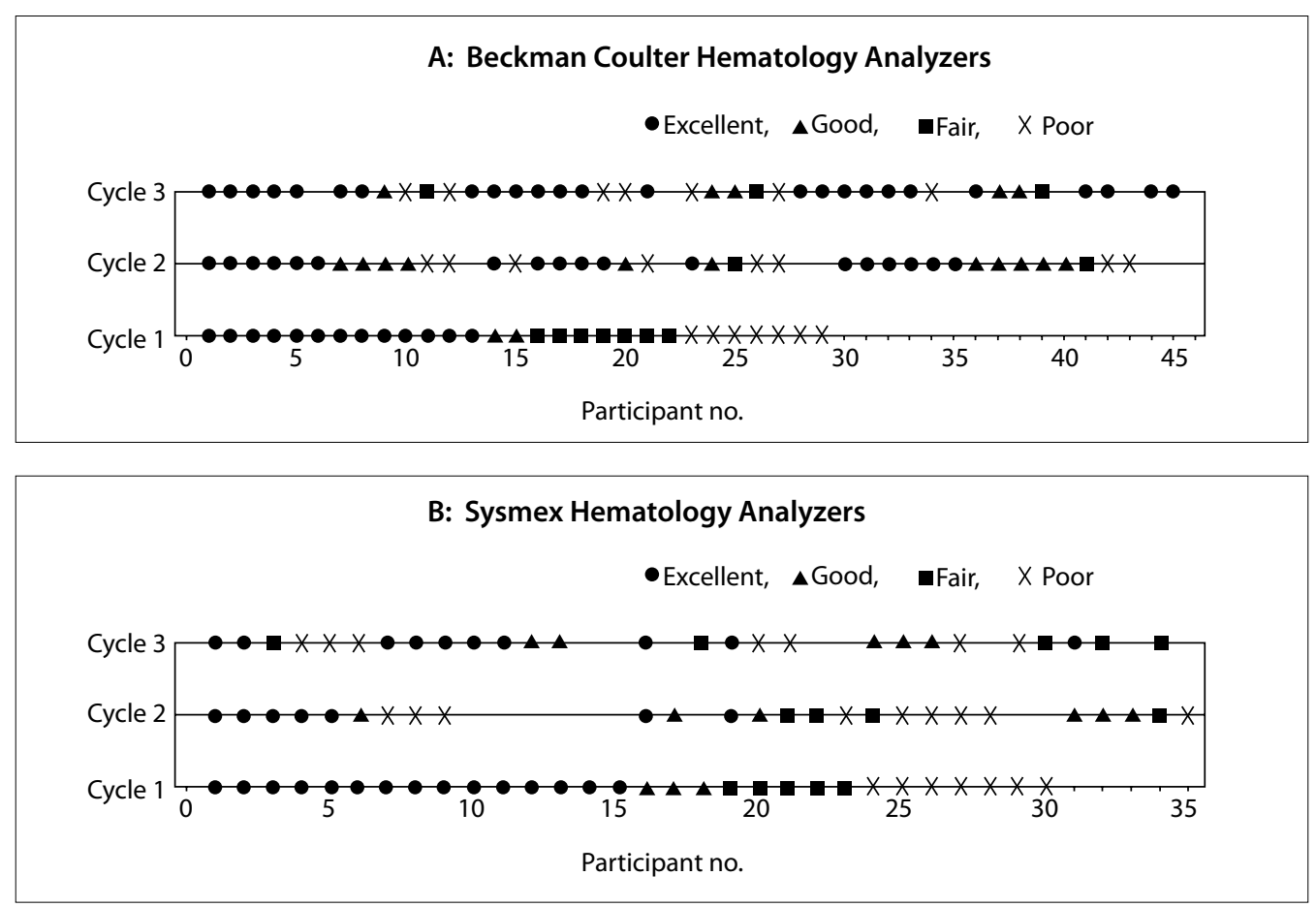

FigURE 4. Graphic summary of performance level of each participant obtained from 3 cycles for A: Beckman Coulter and B: Sysmex hematology analyzers.

$\mathrm{Y}$ - and X-axes represent performance level, and participant number, respectively. Symbols used to indicate the four levels are as follows; : Excellent, $\mathbf{\Delta}$ : Good, $\mathbf{\square}:$ Fair, and x: Poor. 
In addition to MCV and MCH, DCIP test is also necessary for identifying individuals with $\mathrm{Hb} E$ $(5,6,13,14)$. Although the test is simple and rapid, the result is highly observer dependent and adequate practice is required before performing the test (15). Results from this PT program showed that some participants performed DCIP test incorrectly (Table 5). We observed that in comparison to provincial hospitals, participants from smaller hospitals in the community performed the test with less accuracy. In consistent with this finding, we also observed a high rate of incorrect DCIP results in referred samples from community hospital for confirmation of thalassemia at our centre. This is not unexpected because with limited resources and budgets and high routine workload, staffs of these community hospitals usually have lower chance of training. Nonetheless, without the PT program they would not know their performance on thalassemia screening. The test is used widely in Thailand and currently distributed to the low-middle income countries nearby $(5,6,12,16)$. This information would therefore make the health staff recognize the limitation of the test.

Competency in interpretation of screening results and assessment of foetal risk for severe thalassemias are other issues being evaluated. Whether laboratory staffs understand the results is crucial for communicating with the couple and other allied health personals at the hospitals, especially for genetic disease (17). Also, knowing the risk of the expecting foetus of the screened couples will certainly allow them to realize the importance of the accurate screening results. Under this PT program, it was found that approximately $1 / 3$ of participants in the first round interpreted thalassemia screening incorrectly. Although no statistical significance was achieved, it appears that incorrect results decreased gradually during the second and for $1 / 5$ in the third cycle. This may reflect an improvement in the interpreting skill of laboratory staff and support the benefit of the PT program.

In contrast to the competency in interpretation of screening results, incorrect assessment of foetal risk fluctuated from cycle to cycle. It is noteworthy that a proportion of incorrect risk assessment was particularly high for the second cycle of the PT scheme. This can be explained by the fact that in the second cycle, more complex cases were supplied. Both PT items were positive for MCV \& MCH. Only one of them was positive for the DCIP test (Tables 3 and 4). Therefore, based on the screening results, the husband was suspected carrier of a- or $\beta$-thalassemia whereas the pregnant woman could be carrier of $\alpha$ - or $\beta$-thalassemia or $\mathrm{Hb} \mathrm{E}$ (5). Accordingly, the expecting foetus could be at risk of having all the 3 thalassemia diseases including $\mathrm{Hb}$ Bart's hydrops fetalis, $\beta$-thalassemia major and $\mathrm{Hb}$ E- $\beta$-thalassemia. Unfortunately, many participants reported the risk of having only one or two diseases. This reflects in part insufficient knowledge among participants. As for the DCIP test mentioned above, most of the misinterpretation and incorrect assessment of foetal risk were from community hospitals.

There are several approaches to evaluate the overall performance of participants. For thalassemia prevention and control program, we believe that detection of carriers of severe thalassemia, providing accurate interpretation of laboratory results and risk assessment of the corresponding inheritance and interaction are very important. These would require appropriate knowledge of the pathophysiology, genetic inheritance, and genotype-phenotype interactions of the diseases. As for other genetic disorders, it is necessary to have accurate laboratory results as well as accurate interpretation and risk assessment (17). In this study, we combined the accuracy of screening test and the competency in interpretation and risk assessment as the performance criteria. On average, only half of participants had excellent performance (Figure 3). Taking all evaluated items into account, the main reasons explaining the poor performance appear to be incorrect interpretation and risk assessment of the expecting foetus. Similarly, misinterpretations and risk assessments were also observed previously in a PT program on $\mathrm{Hb}$ analysis (18). Because different cases with different complexity were assigned in each cycle, it is therefore not surprising that several laboratories could not maintain their excellent performance. Performance of some participants even swung up and down (Figure 4). Our results indicate that the PT 
program should be continuously operated in parallel with extensive education program on thalassemia screening to all laboratories to warrant the better understanding and maintain the goal of the PT program.

To our best knowledge, only a few papers concerning PT programs for thalassemia have been published. Proficiency testing of hemoglobinopathy techniques in Ontario laboratories initiated in 1989 focused on the accuracy of screening test for sickle cell disease and $\mathrm{Hb}$ electrophoresis (19). More recent study of external quality assessment conducted in Italy focused on $\mathrm{Hb} \mathrm{A}_{2}$ measurement and genotyping of $\beta$-thalassemia $(20,21)$. The Dutch Foundation for Quality Assessment in Medical Laboratories (SKML) currently provides international PT program for thalassemia by assessing the accuracy of $\mathrm{Hb} \mathrm{A_{2 }}$ and $\mathrm{Hb} F$ as well as diagnostic skill of participants (22). In Thailand, the first PT program of $\mathrm{Hb}$ analysis in prevention and control of severe thalassemia has been initiated since 2012 (18). Yet, the program does not include the assessment of initial screening performance and competency of laboratory staff in interpretation and risk assessment, which is the first step that can affect the success of thalassemia prevention.
Our study has some limitations. Firstly, as we used human blood for preparing the PT items, we therefore could not provide a large batch of samples for a larger number of participants; explaining why only members of two haematology manufacturers were invited and why we could not use the same PT items for the 2 groups of participants. Secondly, even though PT items were sent to participants under appropriate conditions and packaging, they were sometimes deteriorated during transportation, leading to a withdrawal of participants, particularly for community hospitals. Nevertheless, the study provides a model of PT program for thalassemia screening and emphasizes a need for setting up such a PT scheme to get a better achievement of prevention thalassemia in this region.

\section{Acknowledgements}

This work was supported by the National Research University program of Khon Kaen University and the Office of the Higher Education Commission, Ministry of Education, Thailand (NRU592015). We thank all individuals donating their blood samples for preparation of PT items used in this study.

\section{Potential conflict of interest}

None declared.

\section{References}

1. William $T N$, Weatherall $D J$. World distribution, population genetics, and health burden of the hemoglobinopathies. Cold Spring Harb Perspect Med 2012;2:a011692. https://doi. org/10.1101/cshperspect.a011692

2. Fucharoen S, Winichagoon P. Haemoglobinopathies in Southeast Asia. Indian J Med Res 2011;34:498-506.

3. Fucharoen $S$, Weatherall DJ. Progress toward the control and management of the thalassemias. Hematol Oncol Clin North Am 2016;30:359-71. https://doi.org/10.1016/j. hoc.2015.12.001

4. Yamsri S, Sanchaisuriya K, Fucharoen G, Sae-Ung N, Ratanasiri $T$, Fucharoen S. Prevention of severe thalassemia in northeast Thailand: 16 years of experience at a single university center. Prenat Diagn 2010;30:540-6. https://doi. org/10.1002/pd.2514

5. Sanchaisuriya K, Fucharoen S, Fucharoen $G$, Ratanasiri $T$, Sanchaisuriya $P$, Changtrakul $Y$, et al. A reliable screening protocol for thalassemia and hemoglobinopathies in pregnancy: an alternative approach to electronic blood cell

counting. Am J Clin Pathol 2005;123:113-8. https://doi. org/10.1309/FUF9EVGQ24V1PKTP

6. Fucharoen G, Sanchaisuriya K, Sae-Ung N, Dangwibul S, Fucharoen $S$. A simplified screening strategy for thalassaemia and haemoglobin $E$ in rural communities in south-east Asia. Bull World Health Organ 2004;82:364-72.

7. Zehnder L, Schulzki T, Goede JS, Hayes J, Reinhart WH. Erythrocyte storage in hypertonic (SAGM) or isotonic (PAGGSM) conservation medium: influence on cell properties. Vox Sang 2008;95:280-7. https://doi.org/10.1111/j.14230410.2008.01097.x

8. International Organizational for Standardization (ISO). ISO/IEC 17043 Conformity assessment - General requirements for proficiency testing. ISO: Switzerland; 2010.

9. Chaitripop $C$, Sanchaisuriya $K$, Inthavong $S$, Fucharoen $G$, Sanchaisuriya $P$, Changtrakun $Y$, Fucharoen S. Thalassemia screening using different automated blood cell counters: consideration of appropriate cutoff values. Clin Lab 2016;62:545-52. 
10. International Organization for Standardization (ISO). ISO 13528: Statistical methods for use in proficiency testing by interlaboratory comparisons. ISO: Switzerland; 2005.

11. Fucharoen G, Srivorakun H, Singsanan S, Fucharoen S. Presumptive diagnosis of common haemoglobinopathies in Southeast Asia using a capillary electrophoresis system. Int J Lab Hematol 2011;33:424-33. https://doi.org/10.1111/ j.1751-553X.2011.01301.x

12. Savongsy O, Fucharoen S, Fucharoen G, Sanchaisuriya K, Sae-Ung N. Thalassemia and hemoglobinopathies in pregnant Lao women: carrier screening, prevalence and molecular basis. Ann Hematol 2008;87:647-54. https://doi. org/10.1007/s00277-008-0490-z.

13. Winichagoon $P$, Thitivichianlert $A$, Lebnak T, Piankijagum $A$, Fucharoen S. Screening for the carriers of thalassemias and abnormal hemoglobins at the community level. Southeast Asian J Trop Med Public Health 2002;33(Suppl 2):145-50.

14. Chaibunruang A, Pornphannukool S, Sae-Ung N, Fucharoen $G$, Sanchaisuriya $K$, Fucharoen S. Improvement of alpha(0)-thalassemia screening using combined osmotic fragility, dichlorophenolindophenol and $\mathrm{Hb} \mathrm{H}$ inclusion tests. Clin Lab 2010;56:111-7.

15. Chapple L, Harris A, Phelan L, Bain B. Reassessment of a simple chemical method using DCIP for screening for haemoglobin E. J Clin Pathol 2006;59:74-6. https://doi. org/10.1136/jcp.2005.027961

16. Wiwanitkit V, Suwansaksri J, Paritpokee N. Combined onetube osmotic fragility (OF) test and dichlorophenol-indolphenol (DCIP) test screening for hemoglobin disorders, an experience in 213 Thai pregnant women. Clin Lab 2002; $48: 525-8$.
17. Hasting RJ, Howell RT. The importance and value of EQA for diagnostic genetic laboratories. J Commun Genet 2010;1:11-7. https://doi.org/10.1007/s12687-010-0009-x

18. Karnpean R, Fucharoen G, Pansuwan A, Changtrakul D, Fucharoen $S$. A proficiency testing program of hemoglobin analysis in prevention and control of severe hemoglobinopathies in Thailand. Clin Chem Lab Med 2013;51:1265-71. https://doi.org/10.1515/cclm-2012-0588

19. Lafferty J, Ali MA, Carstairs K, Crawford L. Proficiency testing of hemoglobinopathy techniques in Ontario laboratories. Am J Clin Pathol 1997;107:567-75. https://doi.org/10.1093/ ajcp/107.5.567

20. Paleari R, Giambona A, Cannata M, Leto F, Maggio A, Mosca A. External quality assessment of hemoglobin A2 measurement: data from an Italian pilot study with fresh whole blood samples and commercial HPLC systems. Clin Chem Lab Med 2007;45:88-92. https://doi.org/10.1515/ CCLM.2007.002

21. Tosto F, Salvatore M, Falbo V, Floridia G, Censi F, Bombieri C, et al. The Italian scheme of External Quality Assessment for beta-thalassemia: genotyping and reporting results and testing strategies in a 5-year survey. Genet Test Mol Biomarkers 2009;13:31-6. https://doi.org/10.1089/gtmb.2008.0072

22. SKML. Assessment of the ability to recognize hemoglobin variants: Qualitative and quantitative aspects. Available at: https://www.skml.nl/en/rondzendingen/overzicht/ rondzending?id=147. Accessed April 4, 2017. 